University of Nebraska - Lincoln

DigitalCommons@University of Nebraska - Lincoln

Agronomy \& Horticulture -- Faculty Publications

Agronomy and Horticulture Department

5-1994

\title{
The Influence of Plant Population Spatial Arrangement on Individual Plant Yield
}

John L. Lindquist

University of Nebraska-Lincoln, jlindquist1@unl.edu

D. Rhode

University of Minnesota, St. Paul

K. J. Puettmann

University of Minnesota, St. Paul

B. D. Maxwell

University of Minnesota, St. Paul

Follow this and additional works at: https://digitalcommons.unl.edu/agronomyfacpub

Part of the Plant Sciences Commons

Lindquist, John L.; Rhode, D.; Puettmann, K. J.; and Maxwell, B. D., "The Influence of Plant Population Spatial Arrangement on Individual Plant Yield" (1994). Agronomy \& Horticulture -- Faculty Publications. 380.

https://digitalcommons.unl.edu/agronomyfacpub/380

This Article is brought to you for free and open access by the Agronomy and Horticulture Department at DigitalCommons@University of Nebraska - Lincoln. It has been accepted for inclusion in Agronomy \& Horticulture -Faculty Publications by an authorized administrator of DigitalCommons@University of Nebraska - Lincoln. 


\title{
THE INFLUENCE OF PLANT POPULATION SPATIAL ARRANGEMENT ON INDIVIDUAL PLANT YIELD ${ }^{1}$
}

\author{
J. L. Lindouist, D. Rhode, K. J. Puettmann, ${ }^{2}$ And B. D. Maxwell ${ }^{3}$ \\ Department of Agronomy and Plant Genetics, University of Minnesota, St. Paul, Minnesota 55108 USA
}

\begin{abstract}
Two greenhouse experiments were conducted to evaluate the performance of individual oat (Avena sativa) target plants as influenced by neighbor oat plants with different spatial arrangements. Crop spatial arrangement was separated into three components: (1) population density, (2) distance between plants (distance dispersion, DD), and (3) angular arrangement of plants about one another (angular dispersion, AD). Distance dispersion was quantified using a weighted mean distance from a target individual to its neighbors. Angular dispersion of neighbors around the target was quantified using a measure of circular variance. DD and $\mathrm{AD}$ were combined to create a dispersion index (DI). At constant density, distance dispersion treatments were combined with angular dispersion treatments in a randomized-block factorial design. Target plant biomass production was predicted using a rectangular hyperbola equation including population density, $\mathrm{DD}, \mathrm{AD}$, and DI as independent variables. Fifty-five and $44 \%$ of the residual variation (the variation not accounted for by density alone) in individual plant yield was accounted for when spatial arrangement (DI) was added to the regression. The approach can be used to compare the intensity of competition among different crop planting patterns.
\end{abstract}

Key words: angular dispersion; crop breeding; crop planting pattern; distance dispersion; neighborhood analysis; selection.

\section{INTRODUCTION}

The development of economically viable, environmentally benign weed management strategies is a major challenge facing agriculture today (Liebman and Dyck 1993). Selecting genetic lines of crop species that will interfere with the growth of weedy species may be an important component of an integrated weed management (Jordan 1993). To develop a screening methodology that will allow breeders to select more competitive crop plants, the factors that account for variation in plant performance (biomass and reproductive yield) in populations must be assessed (Garrity et al. 1992).

Plant spatial arrangement, or planting pattern, may be an important factor determining individual crop plant performance (Mead 1966, Smith et al. 1970, Pant 1979, Soetono and Puckridge 1982, Auld et al. 1983, Hayward and Vivero 1984). To improve the screening process, a methodology must be developed to quantify spatial arrangement as a source of variation in plant growth.

Spatial arrangement has been quantified as the mean rectangularity, or the ratio of distance between rows to

\footnotetext{
${ }^{1}$ Manuscript received 28 November 1992; revised 1 September 1993; accepted 2 September 1993.

${ }^{2}$ Present address: Department of Forest Resources, University of Minnesota, St. Paul, Minnesota 55108 USA.

${ }^{3}$ Present address: Plant and Soil Science Department, Montana State University, Bozeman, Montana 59717 USA.
}

the distance between plants within a row (e.g., Fawcett 1964, Nerson 1980, Jaaffar and Gardner 1988, Sutherland et al. 1989). The influence of rectangularity has been quantified by measuring mean population yield rather than individual plant yield within the population. This method ignores the possibility of nonregular planting patterns, such as occurs in broadcast or solidseeded plantings, or in natural plant populations.

Mead (1966) and Fischer and Miles (1973) incorporated spatial arrangement into a competition index by allocating a polygonal area of land to each plant. The corners of the polygon were determined as a function of the location of neighbor plants. While this method has been used in forestry (Moore et al. 1973, Nance et al. 1988), it is complicated in practice and assumes no sharing of space by neighboring plants.

More recently, researchers have separated plant population spatial arrangement into three distinct components: (1) population density, (2) distance between plants (distance dispersion), and (3) angular arrangement of plants about one another (angular dispersion) (Mack and Harper 1977, Weiner 1984, Silander and Pacala 1985, Wagner and Radosevich 1991).

The objectives of this research were to: (1) determine whether varying distance dispersion and angular dispersion at constant density influence individual oat plant biomass production and (2) determine the proportion of the variation in individual plant biomass that can be accounted for using quantifications of distance dispersion and angular dispersion as predictors of individual crop plant performance. 


\section{MATERIALS AND METHODS}

\section{Model development}

A single-parameter hyperbolic equation (Weiner 1982, Silander and Pacala 1985, Pacala and Silander 1987) has been used to model the response of an individual plant to the density of its neighbors:

$$
S=\frac{M}{(1+c \cdot N)},
$$

where $S=$ biomass production per plant, $M=$ maximum biomass production of an individual in the absence of competition, $c=$ the rate-of-decay parameter, and $N=$ local density (excluding the target individual, under the assumption that it does not compete with itself). Since density was held constant in our experiment, Eq. 1 may be expanded to include additional components of spatial arrangement as independent variables without including additional estimated parameters such that:

$$
S=\frac{M}{(1+c \cdot N \cdot W)},
$$

where $W$ will represent distance dispersion (DD), angular dispersion (AD), or the dispersion index (DI).

The influence of neighboring crop plants on a target individual can be expected to decline as their distance from the target increases. Using a neighborhood approach, Silander and Pacala (1985) quantified distance dispersion (DD) as a weighted mean distance from a target individual to its neighbors:

$$
\mathrm{DD}=\frac{\sum_{i=1}^{N}\left(1-\frac{d_{i}}{r}\right)^{\Theta}}{N},
$$

where $d_{i}=$ the distance to the $i^{\text {th }}$ neighbor, $r=$ the neighborhood radius, $N=$ neighborhood density (excluding the target individual), and $\Theta=$ a distance weighting variable. Weiner (1982) suggested that the decline in effect on the target plant may be a function of the square of the distance of neighbors from the target. In Eq. 3, the exponent $\Theta$ provides for several different functional forms for the weighting of distance. Silander and Pacala (1985) incorporated DD into Eq. $2(W=\mathrm{DD})$ and used least-squares nonlinear regression analysis to fit the model using a range of $\Theta$. The optimum $\Theta$ value can be identified as the value at which the coefficient of determination $\left(r^{2}\right)$ is maximum.

Mack and Harper (1977) proposed a method of quantifying the degree of aggregation of neighbor plants about a target individual based on the work of Zar (1974). This method has been shown to overestimate angular dispersion when neighbors are in clumps (Puettmann et al. 1993). Puettmann et al. (1993) have developed an alternative method of quantifying angular dispersion using the difference between azimuths of adjacent neighbor plants rather than the azimuths themselves to characterize the distribution of neighbors. The variance of these differences is then compared to the most concentrated distribution (all neighbors at the same azimuth) with the same number of neighbor plants.

The angular difference between adjacent plants is calculated as:

$$
\alpha_{i}= \begin{cases}\sigma_{i+1}-\sigma_{i} & \text { for } i=1,2, \ldots N-1 \\ 360^{\circ}-\sigma_{i}+\sigma_{1} & \text { for } i=N,\end{cases}
$$

where $\sigma_{i}$ is the azimuth of neighbor plant $i$ as referenced by the target, $\alpha$ is the angular difference between adjacent points, and $N=$ neighborhood density (excluding the target individual). The variance of an angular distribution is thus:

$$
\delta=\frac{\sum_{i=1}^{N}\left(\alpha_{i}-\mu\right)^{2}}{N-1},
$$

where $\mu$ is the mean angular difference $\left(360^{\circ} / N\right)$. After calculating the variance for the treatment distribution $\left(\delta_{t}\right)$ and for the most concentrated distribution $\left(\delta_{c}\right)$, angular dispersion (AD) is calculated using the ratio between the two distributions:

$$
\mathrm{AD}=1-\frac{\delta_{t}}{\delta_{c}}
$$

$\mathrm{AD}$ will be 1 for the most dispersed distribution and 0 for the most concentrated distribution (Puettmann et al. 1993).

For simplicity, a combined estimate of both distance and angular dispersion is desirable. Finding an interaction between neighbor distance and angular arrangement, Mack and Harper (1977) presented a model that linked angular and distance dispersion with the size of neighbors within concentric annuli around the target to obtain a competitive index. We have developed an overall dispersion index (DI) that links distance dispersion with angular dispersion. Distance to neighbors is measured utilizing concentric annuli and AD calculated for each annulus. DD and AD are then combined in the form:

$$
\mathrm{DI}=\frac{\sum_{j=1}^{4}\left[\left(1-\frac{d_{j}}{r}\right)^{\Theta} \cdot n_{j} \cdot \mathrm{AD}_{j}\right]}{N}
$$

where $d_{j}$ is the distance to the $j^{\text {th }}$ annulus, $r=$ the neighborhood radius, $\Theta$ is the distance-weighting variable, $n_{j}$ is the number of neighbors included within the $j^{\text {th }}$ annulus, $\mathrm{AD}_{j}$ is the angular dispersion value for neighbors within annulus $j$, and $N$ is the neighborhood density (excluding the target plant).

\section{Greenhouse experiments}

Greenhouse experiments were conducted during June, July, and August 1991 and March, April, and 


\section{Distance Dispersion (cm)}
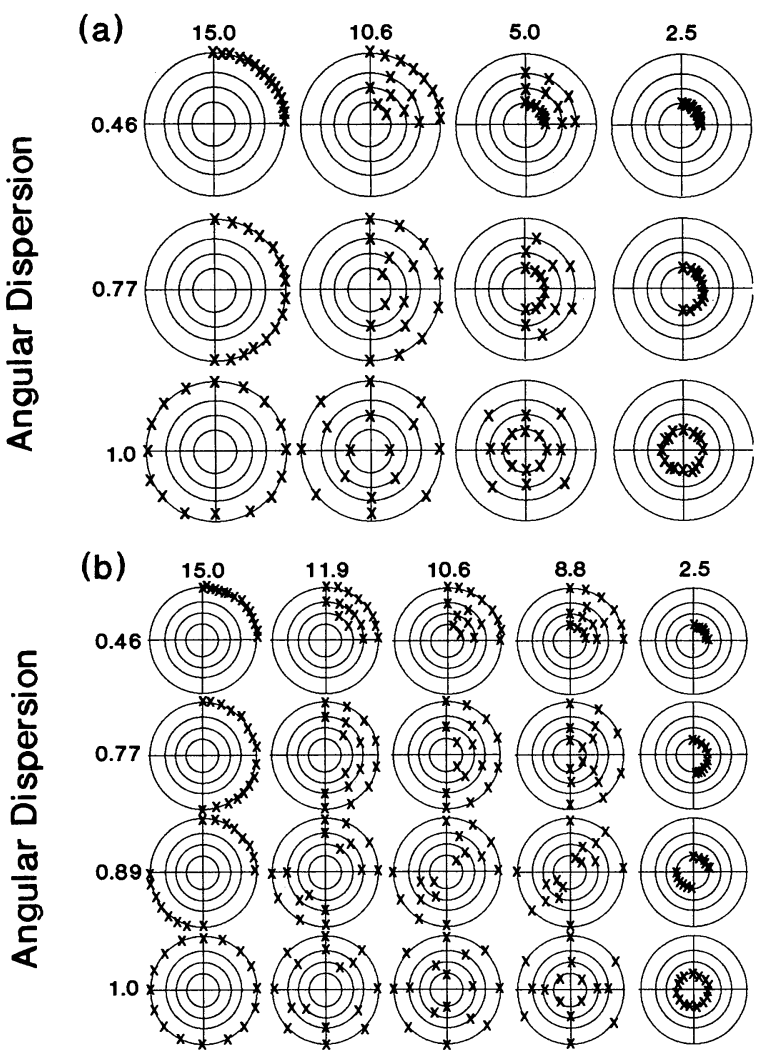

FIG. 1. An illustration of all treatment combinations used in experiments 1 (a) and 2 (b). Distance dispersion treatments (columns of concentric circles) are expressed as the mean (unweighted) distance $(\mathrm{cm})$ of neighbor oat plants from a central target individual. Angular dispersion treatments (rows of concentric circles) were calculated using Eqs. 4, 5, and 6. A $x$ signifies the location of a neighbor oat plant. The target is located at the focus of the concentric circles.

May 1992 to evaluate the performance of individual oat target plants as influenced by neighbor oat plants with different spatial arrangements. Oat (Avena sativa L., cultivar Starter) plants were grown in flats $(36 \times$ $52 \times 6 \mathrm{~cm})$ in equal volumes of steam-treated 1:1:1 soil : sand : peat mixture. Plant density was held constant at 91 plants $/ \mathrm{m}^{2}$ (17 plants per flat, including the target individual). Emergence time and spatial arrangement were controlled by planting single seeds $1.5 \mathrm{~cm}$ deep through pre-marked plastic templates. Seeds that did not germinate by $10 \mathrm{~d}$ after planting were replaced with seedlings transplanted using excess plants. Greenhouse temperatures ranged from $21^{\circ}$ to $38^{\circ} \mathrm{C}$ and from $18^{\circ}$ to $29^{\circ} \mathrm{C}$ during the first and second experiments, respectively. Plants were grown under a 14:10 day: night light regime and watered daily. At maturity, target plants were cut at the soil surface, bagged, and dried at $35^{\circ} \mathrm{C}$ for $10 \mathrm{~d}$. Aboveground biomass $(S)$ and seed yield per target individual were then determined.

In the first experiment, four distance dispersion treatments were combined in a factorial with three angular dispersion treatments, each treatment combination with five replicates (Fig. 1a). In the second experiment, five distance dispersion treatments were combined in a factorial with four angular dispersion treatments, each treatment combination with three replicates (Fig. 1b). Five flats with single plants, individuals in the absence of competition, were planted in each experiment. Flats were arranged in a completely randomized design initially and moved weekly to homogenize any location effects within the greenhouse.

Distance dispersion treatments were established by selecting four concentric circles $(2.5,5.0,10.0$, and 15.0 $\mathrm{cm})$ from a central target plant and growing specific numbers of neighbor plants on each circle (Fig. 1a and b). Angular dispersion treatments were established by dividing the circles into four quadrants with the target individual at the focus and growing neighbors at specific angles within one, two, or all four quadrants. Angular dispersion was then calculated for each treatment using Eqs. 4, 5, and 6.

\section{Analysis}

Linear and nonlinear models were fit to the data in each experiment using regression analysis in PC/SAS (SAS 1988, PROC REG, and PROC NLIN). The coefficient of determination $\left(r^{2}\right)$ was chosen as an appropriate measure to evaluate the goodness of fit of each model. When nonlinear regression (PROC NLIN) was used, the $r^{2}$ was approximated using one minus the ratio of the residual sum of squares to the corrected total sum of squares. The corrected total sum of squares is equivalent to the residual sum of squares obtained using density alone (Eq. 1) as the independent variable. The $r^{2}$ thus calculated defines the amount of the variation not accounted for by density, which is accounted for by adding spatial arrangement (DD, AD, or DI) to the model.

\section{RESULTS}

\section{Relationship between seed yield and aboveground biomass production}

Target plant seed yield was regressed on aboveground biomass production per plant across all treatments in each experiment. The resulting linear models (Fig. 2) were significant $(P<.001)$, accounting for 79 and $99 \%$ of the variation in seed yield for experiments 1 and 2 , respectively. We therefore assumed that the influence of spatial arrangement on seed yield was closely related to its influence on biomass production. Mean biomass production per target plant observed for each treatment combination is reported in Table 1.

\section{Distance dispersion}

To determine the proportion of the residual variation in biomass $(S)$ that can be accounted for by the distance dispersion of oat neighbors, DD was incor- 

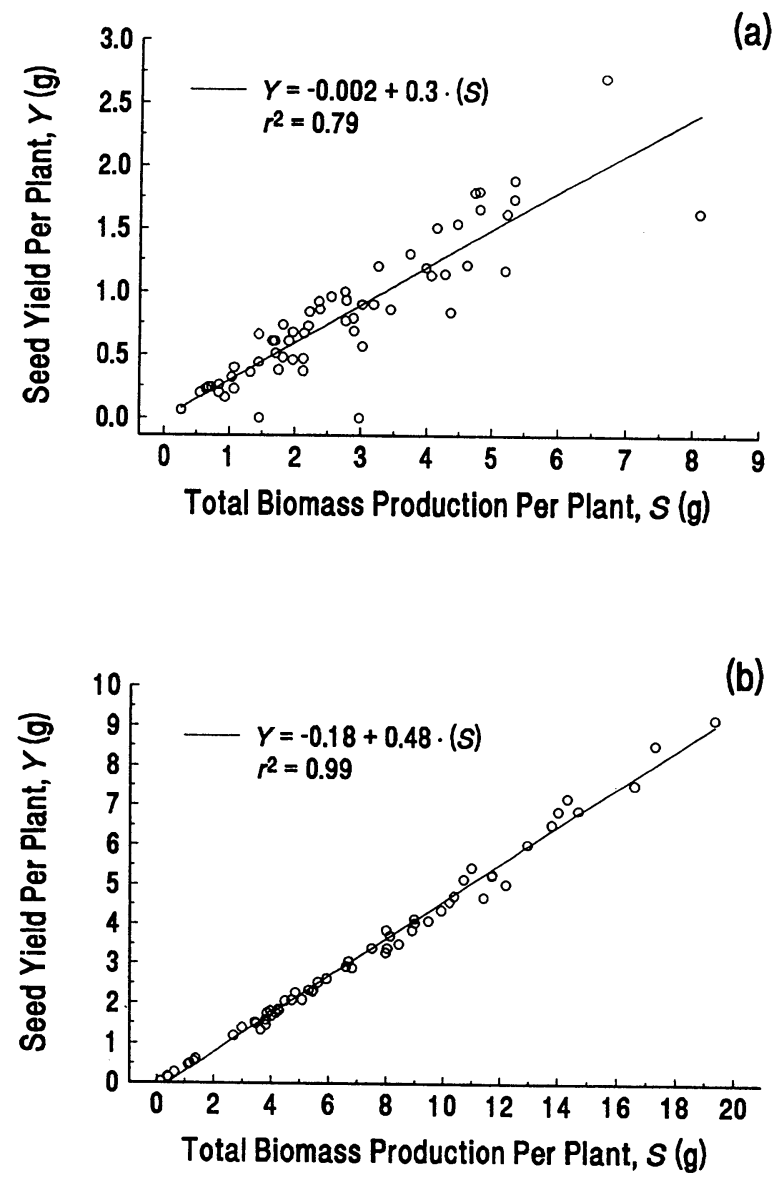

FIG. 2. The relationship between target plant seed yield $(Y)$ and total aboveground biomass $(S)$ for experiments 1 (a) and 2 (b).

porated into Eq. 2 ( $W=\mathrm{DD}) . M$ was calculated as the mean biomass of five individuals grown in the absence of competition (no neighbors) with each experiment, $N=16$ (total density minus the target). Neighborhood radius ( $r$ ) was held constant at $16 \mathrm{~cm}$ to include the influence of all neighbor plants in the analysis. The model was then fit to the data using PROC NLIN (SAS 1988) for each experiment using a range of $\Theta$. The resulting $r^{2}$ values were plotted against $\Theta$ to determine at which value of $\Theta$ the $r^{2}$ is maximized (Fig. 3a).
The $r^{2}$ was maximized in experiment 1 when $\Theta$ was $\approx 0.5$ and in experiment 2 when $\Theta$ was $\approx 0.35$ (Fig. 3a). Thirty-seven and $19 \%$ of the residual variation in aboveground biomass was accounted for using DD as an independent variable in the regressions for experiments 1 and 2 , respectively (Table 2 ).

\section{Angular dispersion}

To determine the proportion of the residual variation in $S$ that can be accounted for by the angular arrangement of oat neighbors, AD as calculated in Eqs. 4,5 , and 6 was also weighted using $\Theta$ and incorporated into Eq. 2 in the form $W=(\mathrm{AD})^{\Theta}$. Again, a range of $\Theta$ values was used in fitting the model to the data, and the resulting $r^{2}$ values were plotted against $\Theta$ (Fig. 3b).

The value of $\Theta$ at which the $r^{2}$ was maximized in both experiments was $\approx 1.0-1.2$ (Fig. $3 \mathrm{~b}$ ), suggesting that weighting AD is not necessary. Twenty and $28 \%$ of the residual variation in aboveground biomass was accounted for using AD as an independent variable in the regressions for experiments 1 and 2, respectively (Table 2).

\section{Combined distance and angular dispersion}

The combined dispersion index (Eq. 7) was also incorporated into Eq. 2 ( $W=\mathrm{DI})$ to determine whether any additional amount of the residual variation in $S$ could be accounted for due to the overall spatial arrangement of neighbors. Since $\mathrm{AD}$ does not require a weighting variable, the model was fit to the data for each experiment using a range of $\Theta$ (distance weighting variable) values. Resulting $r^{2}$ values were plotted against $\Theta$, showing a maximum when $\Theta=0.55$ (Fig. 3c). Fiftyfive and $44 \%$ of the residual variation in aboveground biomass was accounted for using DI as an independent variable in the regressions for experiments 1 and 2, respectively (Fig. 4, Table 2).

\section{DISCUSSION}

Earlier research on the importance of spatial arrangement has shown mixed results. Whereas Wagner and Radosevich (1991) and Pacala and Silander (1990) concluded that the influence of the spatial arrangement of neighbors on individual plant performance was not important in Douglas-fir and short-lived annual sys-

TABLE 1. Mean biomass production (grams per target plant) for all spatial arrangement treatment combinations ( $n=5$ and 3 for experiments 1 and 2, respectively). Distance dispersion treatments (DD) are expressed as the mean (unweighted) distance $(\mathrm{cm})$ of neighbor oat plants from a central target individual. Angular dispersion treatments (AD) were calculated
using Eqs. 4,5 , and 6 .

\begin{tabular}{|c|c|c|c|c|c|c|c|c|c|c|}
\hline \multicolumn{5}{|c|}{ Experiment 1} & \multicolumn{6}{|c|}{ Experiment 2} \\
\hline \multirow[b]{2}{*}{$\mathrm{AD}$} & \multicolumn{4}{|c|}{ DD } & \multirow[b]{2}{*}{$\mathrm{AD}$} & \multicolumn{5}{|c|}{$\mathrm{DD}$} \\
\hline & 15.0 & 10.6 & 5.0 & 2.5 & & 15.0 & 11.9 & 10.6 & 8.8 & 2.5 \\
\hline $\begin{array}{l}0.46 \\
0.77 \\
1.0\end{array}$ & $\begin{array}{l}4.95 \\
4.38 \\
3.60\end{array}$ & $\begin{array}{l}4.67 \\
2.82 \\
1.46\end{array}$ & $\begin{array}{l}2.28 \\
1.14 \\
1.07\end{array}$ & $\begin{array}{l}2.95 \\
2.31 \\
1.41\end{array}$ & $\begin{array}{l}0.46 \\
0.77 \\
0.89 \\
1.0\end{array}$ & $\begin{array}{r}16.88 \\
12.27 \\
3.73 \\
11.06\end{array}$ & $\begin{array}{r}12.35 \\
7.80 \\
4.78 \\
2.29\end{array}$ & $\begin{array}{l}6.22 \\
9.73 \\
3.48 \\
5.47\end{array}$ & $\begin{array}{r}11.27 \\
6.29 \\
6.72 \\
2.58\end{array}$ & $\begin{array}{l}8.16 \\
3.18 \\
4.63 \\
4.15\end{array}$ \\
\hline
\end{tabular}



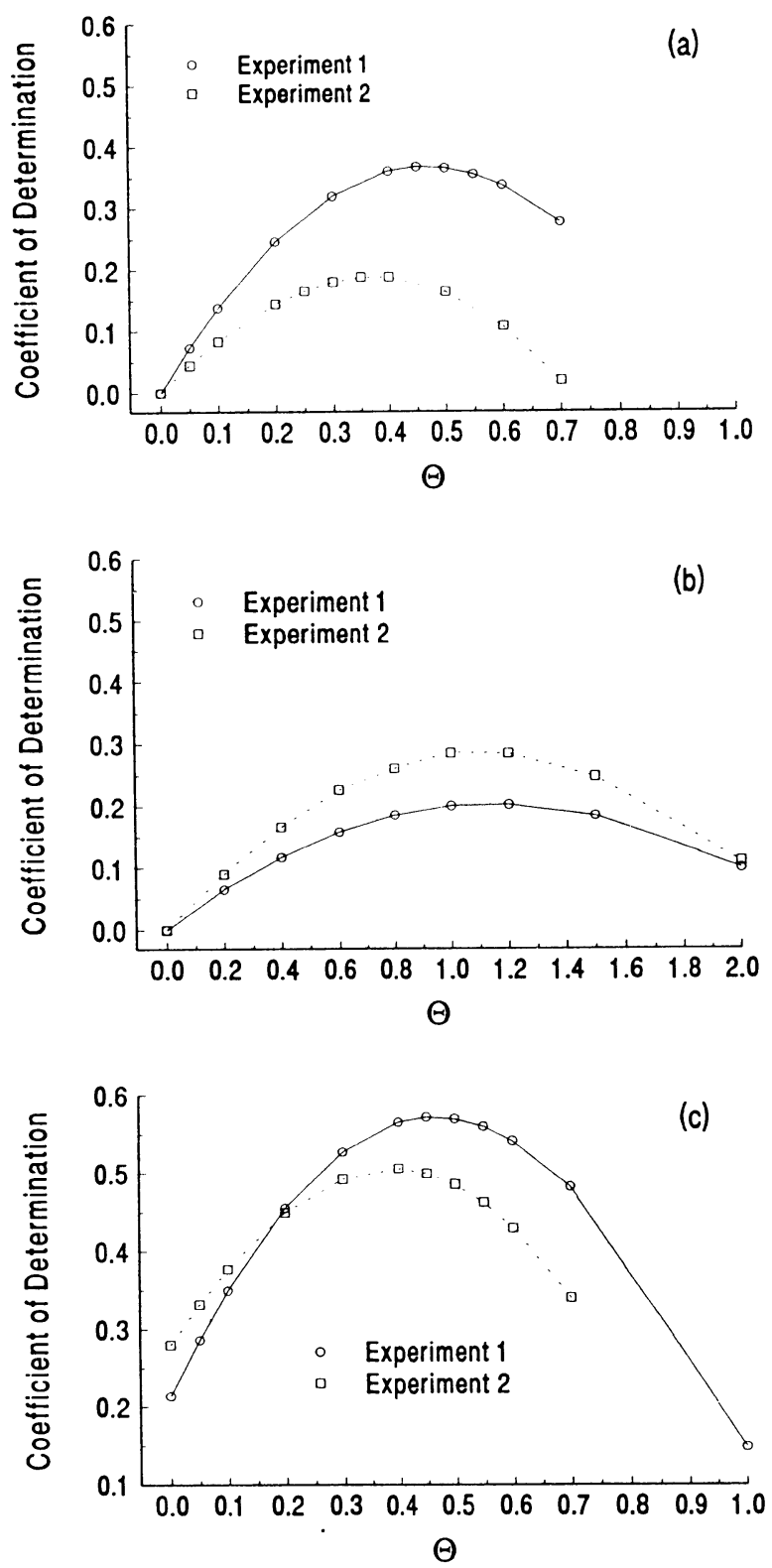

FIG. 3. Coefficients of determination $\left(r^{2}\right)$ obtained from fitting Eq. 2 to the data from experiments $1(O)$ and $2(\square)$. $W$ in Eq. 2 is substituted with DD in (a), $A^{\ominus}$ in (b), and DI in (c). Theta $(\Theta)$ is the weighting variable used in each equation.

tems, Mack and Harper (1977) found it to be highly important in dune annuals.

Our results indicate that oat spatial arrangement, or planting pattern, has a significant influence on the biomass accumulation of individual plants. The close relationship between plant biomass and seed yield (Fig. 2) suggests the importance of population spatial arrangement to the selection of competitive individuals, since the planting pattern within a plant nursery may differ from that which is used in crop production. These results further suggest that spatial pattern within nat- ural populations may influence plant fecundity and therefore the long-term population dynamics of a species. Expanding on the work of others (Mack and Harper 1977, Weiner 1982, 1984, Silander and Pacala 1985, Pacala and Silander 1987), we present a methodology for evaluating the amount of variation in individual plant performance that can be accounted for by two components of spatial arrangement.

Incorporating distance dispersion improved the model fit over using neighbor density alone. We found that the influence of neighbors on the target plant does not decline as a function of the square of the distance as Weiner (1982) suggested. Rather, our results agree closely with the findings of Silander and Pacala (1985), who found the influence of neighbors to decline as a function of the square root of their distance from the target individual. The neighborhood radius used for this study was chosen to include the inter-row distances common to small grain production. Silander and $\mathrm{Pa}$ cala (1985) tested a range of neighborhood sizes, finding an optimum neighborhood radius of $5 \mathrm{~cm}$ for $\mathrm{Ar}$ abidopsis thaliana (L.) Heynh. Our analysis suggested
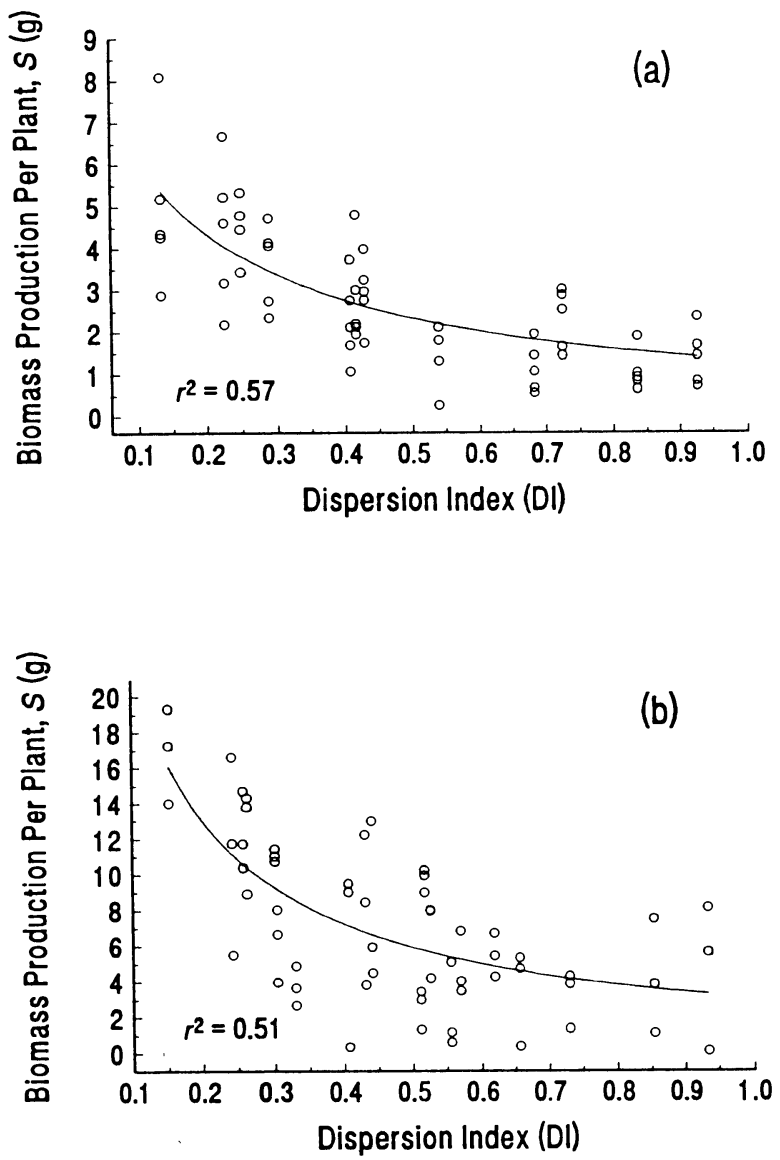

FIG. 4. Aboveground biomass production per plant as the response variable and DI as the independent variable $(W=$ DI) in the nonlinear regression model (Eq. 2). Observed data and predicted line for experiments 1 (a) and 2 (b). 
TABLE 2. Least squares nonlinear regression models using four independent variables $\left(N, \mathrm{DD}, \mathrm{AD}^{\Theta}\right.$, and $\left.\mathrm{DI}\right) . S=$ biomass production (the dependent variable), $M=$ mean dry biomass of five individuals grown in the absence of competition (10.1 and $66.8 \mathrm{~g}$ for experiments 1 and 2 , respectively), $N=$ neighborhood density (=16 plants, excluding the target individual), $\Theta=$ the weighting variable, $c=$ the single estimated parameter, and $r^{2}=$ the coefficient of determination.

\begin{tabular}{|c|c|c|c|c|c|c|}
\hline \multirow[b]{2}{*}{ Model } & \multicolumn{3}{|c|}{ Experiment 1} & \multicolumn{3}{|c|}{ Experiment 2} \\
\hline & $\Theta$ & $c$ & $r^{2}$ & $\Theta$ & $c$ & $r^{2}$ \\
\hline 1. $S=\frac{M}{(1+c \cdot N)}$ & $\cdots$ & $0.17^{*}$ & 0.0 & $\cdots$ & $0.53^{*}$ & 0.0 \\
\hline 2. $S=\frac{M}{(1+c \cdot N \cdot \mathrm{DD})}$ & 0.5 & $0.30^{*}$ & 0.37 & 0.5 & $0.89^{*}$ & 0.19 \\
\hline 3. $S=\frac{M}{\left(1+c \cdot N \cdot \mathrm{AD}^{\ominus}\right)}$ & 1.0 & $0.26^{*}$ & 0.20 & 1.2 & $0.78^{*}$ & 0.28 \\
\hline 4. $S=\frac{M}{(1+c \cdot N \cdot \mathrm{DI})}$ & 0.55 & $9.7^{*}$ & 0.55 & 0.55 & $41.7^{*}$ & 0.44 \\
\hline
\end{tabular}

* Indicates the parameter estimate $(c)$ is significantly different from 0 at $P<0.05$.

that model fit was optimum when using a neighborhood radius of $16 \mathrm{~cm}$ (data not shown). The optimum value found for the distance weighting variable $(\Theta$ in Eq. 3) differed between experiments (Fig. 3a), suggesting that the effect of distance dispersion of neighbors may vary with environmental conditions (note the difference in temperatures between experiments).

Incorporating angular dispersion also improved the model fit, indicating that the influence of oat neighbors on a target individual is greater when they are evenly distributed around the target than when they are grouped to one side. This may be the result of the tendency of plants to grow in the direction of least interference and the indirect effect of interference among neighbors decreasing the effect on the target plant (Ross and Harper 1972, Mack and Harper 1977, Silander and Pacala 1985).

The dispersion index (DI) was shown to be a successful representation of both DD and AD. The improvement in the amount of variation accounted for was nearly additive. An advantage of using DI over the model used by Mack and Harper (1977) is that DI utilizes the azimuth of individual plants rather than grouping neighbors by quadrants.

Our analysis of the importance of plant spatial arrangement is based upon experiments in which density was held constant. While the importance of spatial arrangement may vary with plant density (Watkinson et al. 1983, Matlack and Harper 1986), Silander and Pacala (1985) found that similar measures of angular dispersion and distance dispersion improved model fit (17 and $6 \%$, respectively), given a wide range of plant densities.

Quantifying intraspecific competition effects with spatial arrangement using the equations presented can improve the explanatory power of simple competition models. These models may be used to compare the intensity of competition in different planting patterns. Thus, the models may be useful to plant breeders interested in either maximizing or minimizing the competitive environment for selection purposes.
Environmental conditions in the field are likely to be more heterogeneous than in a greenhouse study, and spatial arrangement as expressed in our models may explain less of the variation in individual plant yield than was achieved here because the models assume a homogeneous environment. This does not suggest, however, that spatial arrangement is less important in heterogeneous environments. Under heterogeneous conditions, spatial arrangement of plants must be referenced against the spatial distribution of resources. By incorporating information such as root distribution, root and shoot growth rates, resource use efficiencies, and the distribution of resources, these models may be expanded to examine the mechanisms that make spatial pattern important. To fully understand competition among individuals, the analysis must also be expanded to include other factors influencing the variation in individual plant yield such as the number of neighbors, their relative sizes, relative emergence time, and the interactions between these factors. The models presented provide a framework for the integration of factors that influence individual plant yield.

\section{ACKNOWLEDGMENTS}

Contribution No. 20195 from the Minnesota Agricultural Experiment Station, St. Paul, Minnesota, USA.

\section{Literature Cited}

Auld, B. A., D. R. Kemp, and R. W. Medd. 1983. The influence of spatial arrangement on grain yield of wheat cultivars, New South Wales. Australian Journal of Agricultural Research 34:99-108.

Fawcett, R. G. 1964. Effect of certain conditions on yield of crop plants. Nature 204:858-860.

Fischer, R. A., and R. E. Miles. 1973. The role of spatial pattern in the competition between crop plants and weeds. A theoretical analysis. Mathematical Biosciences 18:335350 .

Garrity, D. P., M. Movillon, and K. Moody. 1992. Differential weed suppression ability in upland rice cultivars. Agronomy Journal 84:586-591.

Hayward, M. D., and J. L. Vivero. 1984. Selection for yield in Lolium perenne. II. Performance of spaced plant selections under competitive conditions. Euphytica 33:787-800.

Jaaffar, Z., and F. P. Gardner. 1988. Canopy development, 
yield, and market quality in peanut as affected by genotype and planting pattern. Crop Science 28:299-305.

Jordan, N. 1993. Prospects for weed control through crop interference. Ecological Applications 3:84-91.

Liebman, M., and E. Dyck. 1993. Weed management: a need to develop ecological approaches. Ecological Applications 3:39-41.

Mack, R. N., and J. L. Harper. 1977. Interference in dune annuals: spatial pattern and neighborhood effects. Journal of Ecology 65:345-363.

Matlack, G. R., and J. L. Harper. 1986. Spatial distribution and the performance of individual plants in a natural population of Silene dioica. Oecologia (Berlin) 70:121-127.

Mead, R. 1966. A relationship between individual plant spacing and yield. Annals of Botany 30:301-309.

Moore, G. A., C. A. Budelsky, and R. C. Schlesinger. 1973. A new index representing individual tree competitive status. Canadian Journal of Forest Research 3:495-500.

Nance, W. L., G. E. Grissom, and W. R. Smith. 1988. A new weighted and constrained area potentially available. Pages 134-142 in A. R. Ek, S. R. Shifley, and T. E. Burk, editors. Forest growth, modelling and prediction. USDA Forest Service General Technical Report NC-120.

Nerson, H. 1980. Effects of population density and number of ears on wheat yield and its components. Field Crops Research 3:225-234.

Pacala, S. W., and J. A. Silander. 1987. Neighborhood interference among velvetleaf, Abutilon theophrasti, and pigweed, Amaranthus retroflexus. Oikos 48:217-224.

Pacala, S. W., and J. A. Silander. 1990. Field tests of neighborhood population dynamic models of two annual weed species. Ecological Monographs 60:113-134.

Pant, M. M. 1979. Dependence of plant yield on density and planting pattern. Annals of Botany 44:513-516.

Puettmann, K. J., D. Rhode, B. D. Maxwell, and J. L. Lind- quist. 1993. An improved measure of angular dispersion in plant neighborhoods. American Midland Naturalist 130: 401-404.

Ross, M. A., and J. L. Harper. 1972. Occupation of biological space during seedling establishment. Journal of Ecology 60:77-88.

SAS. 1988. SAS/STAT user's guide, release 6.03 edition. SAS Institute, Cary, North Carolina, USA.

Silander, J. A., and S. W. Pacala. 1985. Neighborhood predictors of plant performance. Oecologia (Berlin) 66:256263.

Smith, O. D., R. A. Kleese, and D. D. Stuthman. 1970. Competition among oat varieties grown in hill plots. Crop Science 10:381-384.

Soetono, and D. W. Puckridge. 1982. The effect of density and plant arrangement on the performance of individual plants in barley and wheat crops. Australian Journal of Agricultural Research 33:171-177.

Sutherland, R. A., P. Crisp, and S. M. Angell. 1989. The effect of spatial arrangement on the yield and quality of two cultivars of autumn cauliflower and their mixture. Journal of Horticultural Science 64:35-40.

Wagner, R. G., and S. R. Radosevich. 1991. Neighborhood predictors of interspecific competition in young Douglasfir plantations. Canadian Journal of Forest Research 21: 821-828.

Watkinson, A. R., W. M. Lonsdale, and L. G. Firbank. 1983. A neighborhood approach to self-thinning. Oecologia (Berlin) 56:381-384.

Weiner, J. 1982. A neighborhood model of annual-plant interference. Ecology 63:1237-1241.

1984. Neighborhood interference amongst Pinus rigida individuals. Journal of Ecology 72:183-195.

Zar, J. H. 1974. Biostatistical analysis. Prentice-Hall, Englewood Cliffs, New Jersey, USA. 